\title{
WALORY KRAJOBRAZU LEŚNEGO MAGURSKIEGO PARKU NARODOWEGO A WYKORZYSTANIE POTENCJAtU REKREACYJNEGO
}

\author{
Tomasz Dudek ${ }^{\bowtie}$ \\ Katedra Agroekologii, Uniwersytet Rzeszowski \\ ul. Ćwiklińskiej 1, 35-601 Rzeszów
}

\begin{abstract}
ABSTRAKT
Śledząc dane Głównego Urzędu Statystycznego, możemy zauważyć, że mała liczba odwiedzających Magurski Park Narodowy (40-50 tys. rocznie) utrzymuje się na tym samym poziomie od kilku lat. W pracy podjęto próbę odpowiedzi na pytanie: czy niewielka liczba turystów w Magurskim Parku Narodowym, w którym lesistość wynosi 95\%, wynika z niewyróżniających się walorów krajobrazowych lasów? Badaniami objęto 605 wydzieleń drzewostanowych o łącznej powierzchni 8702 ha, co stanowi 47\% powierzchni leśnej parku. Przeprowadzona waloryzacja krajobrazu leśnego na potrzeby turystyki i rekreacji, pozwala stwierdzić, że małe wykorzystanie potencjału rekreacyjnego Magurskiego Parku Narodowego $(8 \%$ - ustalone we wcześniejszych badaniach) nie wynika z niewielkich walorów krajobrazowych lasów. Większość drzewostanów cechuje się dużymi walorami krajobrazowymi (74\%). Zdaniem autora przyczyny małego zainteresowania tym obszarem należy upatrywać w słabo rozwiniętej infrastrukturze turystycznej, a szczególnie w małej gęstości szlaków $(4,8 \mathrm{~m} / \mathrm{ha})$.
\end{abstract}

Słowa kluczowe: waloryzacja krajobrazu leśnego, turystyka leśna, rekreacja, park narodowy

\section{WSTĘP}

Wszystkie składniki krajobrazu, w tym wartości przyrodnicze, są czynnikiem decydującym o turystycznym zainteresowaniu danym obszarem (Szydłowska i Młynarczyk, 2010). Czym można tłumaczyć utrzymujące się od lat na całym świecie duże zainteresowanie turystyką w parkach narodowych (Gałązka, 2009; Lee i Han, 2002; Obua, 1997) oraz rosnace zainteresowanie turystyką leśną (Destan i Bekiroglu, 2011; Paschalis-Jakubowicz, 2009). Lasy pełnią szczególną rolę, ponieważ są głównym składnikiem atrakcyjności krajobrazu, oprócz rzeźby terenu i wód powierzchniowych (Petrova i in., 2015, Senetra, 2015, Zhang i in., 2015).

Okazuje się, że nie znajduje to potwierdzenia w Magurskim Parku Narodowym (MPN), który można nazwać leśnym ze względu na bardzo wysoką lesistość (95\%). Śledząc dane Głównego Urzędu Statystycznego (Ochrona..., 2010-2014), możemy zauważyć, że mała liczba odwiedzających park (40-50 tys. rocznie) utrzymuje się na tym samym poziomie od kilku lat. Z wcześniejszych badań wynika, że wyliczony potencjał rekreacyjny lasów MPN jest wykorzystany zaledwie w około 8\% (Dudek, 2014). Potencjał rekreacyjny jest wyrażony w naturalnej chłonności rekreacyjnej drzewostanów w osobogodzinach na hektar na dobę, która oznacza liczbę osób mogących przebywać jednocześnie w danym czasie i miejscu bez większego ryzyka uszkodzeń środowiska leśnego.

Celem pracy była ocena walorów krajobrazowych lasów w Magurskim Parku Narodowym na potrzeby

『tdudek80@ur.edu.pl 
turystyki i rekreacji i na jej podstawie próba odpowiedzi na pytanie: czy niewielka liczba turystów wynika z niewyróżniających się walorów krajobrazowych tego obszaru?

\section{MATERIAE I METODY}

Badania przeprowadzono w Magurskim Parku Narodowym położonym $\mathrm{w}$ strefie przejściowej między Karpatami Wschodnimi a Zachodnimi. Badaniami objęto 605 wydzieleń drzewostanowych o łącznej powierzchni 8702 ha, co stanowi $47 \%$ powierzchni leśnej parku.

Park został utworzony w 1995 roku na powierzchni 19439 ha. Usytuowanie parku ma bezpośredni wpływ na bogactwo przyrodnicze. Można tu spotkać m.in. 55 gatunków ssaków, 150 gatunków ptaków i 759 gatunków roślin naczyniowych, w tym wiele chronionych. Przez teren parku przebiega $85 \mathrm{~km}$ szlaków pieszych i $10 \mathrm{~km}$ szlaku konnego stanowiącego odcinek konnej trasy transbeskidzkiej, a także ścieżki rowerowe wyznaczone po drogach publicznych (Zieliński, 2010).

Gęstość szlaków turystycznych w MPN wynosi $4,8 \mathrm{~m} / \mathrm{ha}$ i jest to wartość znacznie mniejsza od średniej wszystkich parków narodowych w kraju 11,4 m/ha (Dudek, 2014).

Park ma charakter typowo leśny, lesistość badanego obiektu jest bardzo wysoka - wynosi 95\%. Najliczniej reprezentowanym zespołem jest żyzna buczyna karpacka, która tworzy charakterystyczny krajobraz parku. Wzdłuż cieków wodnych spotyka się olszynę górską oraz podgórski łęg jesionowy. Uzupełnieniem są jedliny, olsy i nieliczne grądy, a na gruntach porolnych: zbiorowiska olszy szarej, drzewostany sosnowe i mieszane lasy liściaste. Najcenniejsze fragmenty zbliżone do lasów puszczańskich, które są objęte ochroną ścisłą, zajmują 12\% powierzchni (Czaderna, 2009).

Waloryzację krajobrazu leśnego na potrzeby turystyki i rekreacji przeprowadzono zgodnie z metodyką opracowaną przez Rožkova (Ważyński, 1997) i zmodyfikowaną przez Dudka (2016). Krajobraz leśny oceniono z perspektywy wnętrz drzewostanowych na podstawie takich cech drzewostanu, jak: wiek, budowa piętrowa, barwa i kompozycja, skład gatunkowy dendroflory, pokrycie runa, wilgotność siedliska, nachylenie terenu i mozaikowatość krajobrazu.
Dane dotyczące ocenianych cech taksacyjnych drzewostanów pozyskano z operatów ochrony ekosystemów leśnych MPN (Operat..., 1999).

\section{WYNIKI}

Oceniane drzewostany w większości należą do starszych klas wieku. Zaliczane do klasy V i starsze ( $>80$ lat) stanowią $47 \%$ badanej powierzchni parku, drzewostany klasy IV porastają $8 \%$, klasy III (w wieku $41-$ 60 lat $)-20 \%$, a najmłodsze ( $<40$ lat $)-$ pozostałe $25 \%$.

Blisko $70 \%$ lasów w badanej części parku porasta stok spadzisty lub stromy $\left(13-30^{\circ}\right), 26 \%$ - stok pochyły $\left(8-12^{\circ}\right)$, najkorzystniejszy dla najbardziej rozpowszechnionych form rekreacji (spacerowanie, bieganie) (Dudek, 2013), pozostałe 4\% pokrywa stok łagodny, bardzo stromy lub teren równy.

W badanej części parku występuje małe zróżnicowanie siedliskowych typów lasu. Dominującym siedliskiem jest las górski świeży (83\%), a towarzyszącymi: las górski wilgotny (8\%), las łęgowy górski i ols górski (łącznie 9\%).

Duża bioróżnorodność jest domeną waloryzowanych lasów. Drzewostany wielogatunkowe (ponad 10 gatunków drzew i krzewów) stanowią 13\% badanych, drzewostany mieszane (3-5 gatunków panujących drzew i mniej niż 10 gatunków dendroflory) - 42\%, drzewostany mieszane z 2 gatunkami panujących drzew zajmują $36 \%$ powierzchni, a drzewostany jednogatunkowe porastają jedynie 7\% powierzchni. Wyniki przeprowadzonej waloryzacji krajobrazu leśnego MPN zebrano w tabeli 1.

Analizując otrzymane wyniki, można stwierdzić, że drzewostany na badanym terenie cechują się walorami krajobrazowymi: dużymi $(73,87 \%)$ i średnimi $(25,87 \%)$. Drzewostany o małych walorach krajobrazowych odnotowano tylko na 23 ha, a w ogóle nie wystąpiły drzewostany o bardzo małych i bardzo dużych walorach krajobrazowych.

\section{DYSKUSJA}

Matuszewska (2008) zwraca uwagę, że zagospodarowanie turystyczne, oprócz interesujących walorów naturalnych i antropogenicznych, jest głównym czynnikiem wpływającym na wybór miejsca do wypoczynku. Otrzymane w pracy wyniki mogą wskazywać, że 
Dudek, T. (2016). Walory krajobrazu leśnego Magurskiego Parku Narodowego a wykorzystanie potencjału rekreacyjnego. Acta Sci. Pol. Silv. Colendar. Ratio Ind. Lignar., 15(4), 223-227. DOI: 10.17306/J.AFW.2016.4.25

Tabela 1. Wyniki waloryzacji krajobrazu leśnego w badanym obiekcie

Table 1. Results of the forest landscape valorisation in the Magurski National Park

\begin{tabular}{|c|c|c|c|}
\hline $\begin{array}{c}\text { Klasa estetyczności krajobrazu; } \\
\text { suma punktów } \\
\text { Landscape aesthetic class; total points }\end{array}$ & $\begin{array}{c}\text { Liczba wydzieleń } \\
\text { drzewostanowych } \\
\text { Number of separated } \\
\text { tree stands }\end{array}$ & $\begin{array}{l}\text { Powierzchnia } \\
\text { Surface area } \\
\text { ha }\end{array}$ & $\begin{array}{c}\text { Udział } \\
\text { Share } \\
\%\end{array}$ \\
\hline $\begin{array}{l}\text { I bardzo duże walory krajobrazowe; } 39-44 \\
\text { I very high landscape values; } 39-44\end{array}$ & 0 & 0 & 0 \\
\hline $\begin{array}{l}\text { II duże walory krajobrazowe; } 31-38 \\
\text { II high landscape values; } 31-38\end{array}$ & 347 & 6428 & 73,87 \\
\hline $\begin{array}{l}\text { III średnie walory krajobrazowe; } 22-30 \\
\text { III average landscape values; } 22-30\end{array}$ & 248 & 2251 & 25,87 \\
\hline $\begin{array}{l}\text { IV małe walory krajobrazowe; } 22-30 \\
\text { IV low landscape values; } 13-21\end{array}$ & 10 & 23 & 0,26 \\
\hline $\begin{array}{l}\text { V bardzo małe walory krajobrazowe; do } 12 \\
\text { V very low landscape values; up to } 12\end{array}$ & 0 & 0 & 0 \\
\hline
\end{tabular}

nieduże wykorzystanie potencjału rekreacyjnego MPN $(8,1 \%$ - Dudek, 2014) nie wynika z małych walorów krajobrazowych lasów. Większość drzewostanów cechuje się dużymi walorami krajobrazowymi (74\%), aczkolwiek nie odnotowano w badanej części parku drzewostanów wyróżniających się pod tym względem (klasa I - tab. 1).

Wysokie walory krajobrazowe MPN zauważa również Partyka (2010). Przeważający udział drzewostanów o dużych walorach krajobrazowych wynika przede wszystkim z zaawansowanego wieku (blisko połowa przekroczyła 80 lat), korzystnych z punktu widzenia rekreacji siedlisk (83\% stanową siedliska świeże) oraz dużej bioróżnorodności. Dymitryszyn i Schwerk (2009) udowodnili, że atrakcyjne są te krajobrazy, które mają większą liczbę gatunków, a więc bioróżnorodność wzbogaca krajobraz, jest z nim ściśle powiązana (Thies i Tscharntke, 1999). Gibson i in. (2011) również podkreślają, że lasy cechują się wyższym wskaźnikiem różnorodności biologicznej niż inne ekosystemy. Smoleński (2015) natomiast przeprowadził badania ankietowe wśród mieszkańców aglomeracji Białegostoku, z których wynika, że większość respondentów nie akceptuje zamkniętego krajobrazu leśnego i do celów rekreacji poza domem wybiera tereny otwarte $\mathrm{z}$ panoramą leśną.

Należy dodać, że krajobraz MPN jest mało zróżnicowany. Wyraźnie dominującym jego składnikiem są lasy (95\%). Dlatego oferta turystyczna powinna być skierowana do osób poszukujących ciszy w morzu zieleni, nie zaś nastawionych na pocztówkowe widoki. W tym kierunku powinny zmierzać działania promocyjne oraz inwestycje, mające na celu zwiększenie wykorzystania potencjału rekreacyjnego parku, a tym samym poprawę jego kondycji finansowej.

Magurski Park Narodowy odwiedza rocznie ok. 45 tys. turystów. Biorąc pod uwagę roczne obciążenie turystyczne szlaków (478 osób na 1 km szlaku), lokuje to MPN na 6 miejscu od końca wśród wszystkich 23 parków w Polsce. Zwiększenie wykorzystania potencjału rekreacyjnego MPN do poziomu wyliczonego przez Dudka (2014), tj. ok. 500 tys. osób rocznie, z zachowaniem obecnej gęstości szlaków, przesunęłoby park na 6 miejsce od początku wspomnianej listy. Powstałe wówczas obciążenie szlaków turystycznych i tak byłoby blisko czterokrotnie mniejsze niż w Parkach: Wolińskim, Pienińskim i Karkonoskim oraz dwukrotnie mniejsze niż w Tatrzańskim i Ojcowskim. Park charakteryzuje się jedną z najmniejszych gęstości szlaków turystycznych wśród wszystkich parków narodowych w kraju, czyli istnieje w tej sferze pewna niewykorzystana rezerwa. Należy zauważyć, że administracja parku dostrzega ten problem. W 2013 roku w MPN przybyło 9,1 km szlaków turystycznych, co stanowi wzrost o $11 \%$. Wydaje się, że można by wyznaczyć dodatkowe szlaki piesze, z kilkoma punktami 
widokowymi, prowadząc je przez siedliska o możliwie największej naturalnej odporności na uszkodzenia. Jak bowiem zauważa Partyka (2010), właśnie szlak pieszy jest najmniej uciążliwym elementem zagospodarowania parków narodowych.

Prawdą jest, że degradacja krajobrazu wiąże się wprost liniowo $\mathrm{z}$ obciążeniem turystycznym, ale ważną rolę odgrywa wyposażenie w infrastrukturę turystyczną. Okazuje się, że największa degradacja zachodzi przy szlakach $\mathrm{w}$ najmniejszym stopniu wyposażonych w infrastrukturę (Cieszewska i Deptuła, 2013). Dlatego odpowiednie zagospodarowanie turystyczne istniejących i powstających szlaków powinno zapewnić bezpieczeństwo zarówno chronionej przyrody, jak i turystów. Warto zauważyć, że turyści odwiedzający parki narodowe w większości (75\% respondentów) są świadomi, że dla środowiska przyrodniczego są elementem niepożądanym, a nawet intruzem (Gałązka, 2009).

\section{PODSUMOWANIE}

Walory krajobrazowe nie zawsze są czynnikiem gwarantującym zainteresowanie turystyczne danym obszarem. Niewątpliwie krajobraz przeważającej powierzchni leśnej MPN (74\%) wyróżnia się dużymi zaletami, które jednak nie zapewniają większego zainteresowania turystycznego.

Niski poziom infrastruktury turystycznej, zwłaszcza mała gęstość szlaków turystycznych, jest najbardziej prawdopodobną przyczyną niewykorzystania potencjału rekreacyjnego parku (tylko w ok. 8\%). Istotne jest również położenie $\mathrm{z}$ dala od dużych aglomeracji miejskich oraz duża $\mathrm{w}$ tej części Polski lesistość, a więc i konkurencja innych obszarów leśnych.

\section{PIŚMIENNICTWO}

Obua, J. (1997). Environmental impact of ecotourism in Kibale National Park, Uganda. J. Sustainable Tour., 3, 213-223.

Czaderna, A. (2009). Walory Magurskiego Parku Narodowego i ich ochrona. Rocz. Bieszcz., 17, 147-163.

Cieszewska, A., Deptuła, M. (2013). Czynniki wpływające na degradację szlaków turystycznych na terenie Tatrzańskiego Parku Narodowego. Stud. Mat. Centr. Eduk. Przyr.-Leśn., 4(37), 77-82.
Destan, S., Bekiroglu, S. (2011). Evaluation of the territorial system of forest recreation by natural indicators: Belgrade forest example. Afric. J. Agric. Res., 6(1), 212-223.

Dymitryszyn, I., Schwerk, A. (2009). Piękno scenerii krajobrazu - turystyka a różnorodność gatunkowa biegaczowatych - przykład badań z Puszczy Piskiej i Drawieńskiego Parku Narodowego. Stud. Mat. Centr. Eduk. Przyr.-Leśn., 4(23), 100-109.

Dudek, T. (2013). Ocena potencjału rekreacyjnego lasów w terenie o zróżnicowanej orografii na przykładzie Czarnorzecko-Strzyżowskiego Parku Krajobrazowego. Sylwan, 157(10), 775-779.

Dudek, T. (2014). Potencjał rekreacyjny Magurskiego Parku Narodowego a rzeczywista liczba zwiedzających. Sylwan, 158(11), 875-879.

Dudek, T. (2016). Waloryzacja krajobrazu leśnego Czarnorzecko-Strzyżowskiego Parku Krajobrazowego. Przestrzeń i Forma, 26, 187-200.

Lee, Ch. K., Han, S. Y. (2002). Estimating the use and preservation values of national parks' tourism resource using a contingent valuation method. Tourism Manag., 23, 531-540.

Gałązka, M. (2009). Turystyka zrównoważona w parkach narodowych w opinii turystów. Stud. Mat. Centr. Eduk. Przyr.-Leśn., 4(23), 123-130.

Gibson, L., Lee, T. M., Koh, L. P., Brook, B. W., Gardner, T. A., Barlow, J., ..., Sodhi, N. S. (2011). Primary forests are irreplaceable for sustaining tropical biodiversity. Nature, 478, 378-381.

Graja-Zwolińska, S. (2009). Rola wskaźnika chłonności turystycznej w kształtowaniu przestrzeni turystycznej parków narodowych. Stud. Mat. Centr. Eduk. Przyr.-Leśn., 4(23), 187-192.

Matuszewska, D. (2008). Zasady zagospodarowania terenu dla potrzeb turystyki i rekreacji. W: Z. Młynarczyk, A. Zajadacz (red.), Uwarunkowania i plany rozwoju turystyki (s. 77-88). Poznań: Wyd. Nauk. UAM.

Ochrona środowiska (2010-2014). Główny Urząd Statystyczny, Warszawa.

Partyka, J. (2010). Udostępnianie turystyczne parków narodowych w Polsce a krajobraz. Pr. Kom. Krajobr. Kultur., 14, 252-263.

Paschalis-Jakubowicz, P. (2009). Leśnictwo a leśna turystyka i rekreacja. Stud. Mat. Centr. Eduk. Przyr.-Leśn., 4(23), 29-35.

Petrova, E. G., Mironov, Y. V., Aoki, Y., Matsushima, H., Ebine, S., Furuya, K., ..., Ueda, H. (2015). Comparing the visual perception and aesthetic evaluation of natural landscapes in Russia and Japan: cultural and environmental factors. Progr. Earth Planet. Sci., 2, 6. 
Senetra, A. (2015). Las jako istotny komponent przestrzeni w aspekcie opracowywania map wartości krajobrazów wiejskich. Sylwan, 159, 757-766.

Smoleński, M. (2015). Preferencje mieszkańców Białegostoku względem leśnych usług rekreacyjnych - potrzeba odmienności krajobrazowej. Leśn. Pr. Bad., 76(4), 341-349.

Szydłowska, A., Młynarczyk, K. (2010). Krajobrazowe uwarunkowania rozwoju turystyki w Parku Krajobrazowym Wzgórz Dylewskich. Acta Sci. Pol., Administratio Locorum, 9(2), 139-146.

Thies, C.,Tscharntke, T. (1999). Landscape structure and biological control in agro-ecosystems. Science, 285 893-895.
Ważyński, B. (1997). Urządzanie i zagospodarowanie lasu dla potrzeb turystyki i rekreacji. Poznań: Wyd. Akademii Rolniczej.

Zhang, T., Deng, S., Ma, Q., Sasaki, K. (2015). Evaluations of landscape locations along trails based on walking experiences and distances traveled in the Akasawa Forest Therapy Base, Central Japan. Forests, 6, 2853-2878.

Zieliński, K. (2010). Leksykon podkarpackiej przyrody. Rzeszów: Resprint.

Operat ochrony ekosystemów leśnych Magurskiego Parku Narodowego na okres 2000-2019 (1999).

\title{
ASSETS OF FOREST LANDSCAPE IN THE MAGURSKI NATIONAL PARK VERSUS UTILISATION OF TOURIST POTENTIAL
}

\begin{abstract}
An analysis of data from the Central Statistical Office suggests that the low number of people visiting the Magurski National Park (40,000-50,000 a year) has remained the same for several years now. This paper is an attempt at answering a question whether a small number of tourists in the Magurski National Park, where afforestation rate is $95 \%$, is a consequence of rather average landscape assets of the local forests. The research has covered 605 tree stands of a total area of 8,792 ha, which is $47 \%$ of the park's forest surface area. The performed valorisation of the forest landscape from the perspective of tourism and recreation allows to claim that the low utilisation of the recreational potential of the Magurski National Park $(8 \%$ - determined in previous studies) is not a result of modest landscape values of forests. The majority of tree stands boasts high landscape values (74\%). In the author's opinion, the reason for the small interest in this area lies in the underdeveloped tourist infrastructure, especially the low density of trails $(4.8 \mathrm{~m} / \mathrm{ha})$.
\end{abstract}

Key words: forest landscape valorisation, forest tourism, recreation, national park 